\title{
EXERCISE ADDICTION AND ITS RELATION TO PSYCHO-SOCIAL ASPECTS AND MOTIVES
}

\author{
Nadja Walter, Thomas Heinen \\ Leipzig University, Germany \\ E-mail: nadja.walter@uni-leipzig.de, thomas.heinen@uni-leipzig.de
}

\begin{abstract}
Despite typical physiological risks of regular physical activity such as injuries or overtraining, particularly excessive exercise can have psychological side effects and become obsessive. This obsessiveness is often associated with symptoms of addiction (i.e., reduction of other activities, lack of control, withdrawal symptoms). However, the underlying process of developing an exercise addiction is not yet fully understood. Besides the physiological approach, there are several psychological and socio-theoretical models focusing on personal and situational factors. The aim of this research was to explore the role of psycho-social aspects and their influence on symptoms of exercise addiction. 501 participants were asked to record their current sport regarding type, intensity, frequency, and competitive activity. Furthermore, the participants were asked about the motives to exercise as well as their inspiration to start with their current sport. Addictive symptoms were assessed using the Exercise Dependence Scale (EDS). It was expected, that inspiration, competitive activity, as well as the motives achievement striving and catharsis have an influence on the EDS score. The results showed that athletes rating the motives achievement striving, catharsis and enjoyment of movement as important or very important showed significantly higher scores in the EDS. No significant differences were found for inspiration, but competitive activity. The findings suggest an important role of intrinsic motivation on the development of exercise addition, particularly the motive enjoyment of movement. However, the interaction of personal and situational factors needs to be explored further.
\end{abstract}

Keywords: achievement striving, catharsis, competitive athletes, exercise dependence scale, inspiration, physical activity.

\section{Introduction}

For many people, physical activity means fun, health, joy, and leisure time spent with friends. But for some athletes, the positive part of physical activity is no longer the primary goal. It is known that regular physical activity has several physiological and psychological benefits and that it is associated with enhanced health and well-being (Clow \& Edmunds, 2014). Regular exercise is also seen as one crucial component in the primary prevention of chronic diseases and obesity (National Center for Health Statistics, 2012; WHO, 2010). However, when a regular activity becomes excessive, exercise may result in aspects such as injuries, overreaching and 
OF PSYCHOLOGY

IN THE $21^{\text {st }}$ CENTURY Vol. 13, No. 2, 2019

114

overtraining, as well as in anorexia athletica or exercise addiction (Dishman, 1985; Hale, Roth, DeLong, \& Briggs, 2010; Szabo \& Griffiths, 2007). Despite the extensive body of research on exercise addiction, the underlying processes of developing exercise addiction are still not fully understood. Notably, the role of different motives such as catharsis or the influence of peer groups and the coach is still unclear.

Exercise addiction can be defined by seven physiological and psychological criteria (i.e., Diagnostic and Statistical Manual for Mental Disorders, DSM; De Coverley Veale, 1987). Athletes develop a (1) typical tolerance towards the same amount of physical activity. Consequently, they (2) increase (training) frequency and amount intentionally, and (3) invest more time for their training sessions to achieve the same effect. Addicted athletes (4) continue exercising although they are aware of persistent or recurrent physical problems (e.g., injuries). In this context, and due to spending more time with exercise, addicted athletes (5) reduce occupational and particularly social and recreational activities and show (6) significant withdrawal symptoms (e.g., inner restlessness, anxiety, irritability), once they are refused to reduce or stop their training. Finally, addicted athletes show (7) a lack of control in reducing the amount of exercise as well as a persistent desire to continue with exercise (Allegre, Souville, Therme, \& Griffiths, 2006; Hausenblas \& Symons Downs, 2002b).

On the one hand, aspiring athletes may show some of these symptoms, but won't be considered as addicted. The difference between addicted athletes and athletes that are (highly) committed to physical activity is the missing obsessiveness and the lack of control as mentioned above (Allegre et al., 2006; Berczik et al., 2011). Whereas not addicted athletes can reduce or cut down their physical activity (e.g., in case of injuries), addicted athletes often continue with physical activity even if there are some health restrictions. This obsessive motive is related to a so-called encompassing fixation, associated with the development of an ingroup-identity. Affected athletes predominantly surround themselves with persons with the same interest and avoid persons, that do not share their values (Bette \& Gugutzer, 2012).

On the other hand, not addicted athletes differ in their motivation and goal setting from addicted athletes (Breuer \& Kleinert, 2009). In this context, exercise addiction can be further divided into primary and secondary addiction. Primary addiction stands for an independent disease, whereas the secondary addiction is related to an eating disorder and is termed as a co-morbid disease (De Coverley Veale, 1987; Hausenblas \& Symons Downs, 2002b).

Nevertheless, the underlying processes of developing an exercise addiction are not yet fully understood. There are three approaches to explain the development of exercise addiction: 1) the physiological approach, 2) the psychological approach and 3) the socio-theoretical approach. First, the physiological approach emphasizes the sympathetic arousal adaption, the increased plasma opioid peptides or the elevations of beta-endorphin during physical activity (Blake, Stein, \& Vomachka, 1984; Fraioli, Moretti, Paolucci, Alicoccio, \& Crescenzi, 1980; Thompson \& Blanton, 1987). Following this approach, the release of certain hormones is related to an intense feeling of euphoria (Berczik et al., 2011). Second, Szabo (1995; 2010) for example presented a psychological approach, indicating excessive exercising as a way to cope with conflicts and crises. Other researchers found a negative correlation between certain personality traits and exercise addiction (Hausenblas \& Giacobbi, 2004; Hill, Robson, \& Stamp, 2015). Therefore, athletes with low self-esteem and high perfectionism are more likely to develop exercise addiction. Third, in a more socio-theoretical approach, exercise addiction can be seen as a combination of social learning (particularly at a young age), gender roles and values as well as the influence of familiar models, peer groups and the coach. So, it is assumed that for instance girls with a particular pressure from gender roles or peers in a specific sport are more likely to develop exercise addiction as compared to other girls or boys (Bette \& Gugutzer, 2012). Taken the empirical evidence together, Figure 1 shows an extended version of an interactional model postulated by Egorov and Szabo (2013). The model considers the complex set of personal, physiological, motivational, environmental and situational factors to explain exercise addiction. However, the above-mentioned socio-theoretical approach by Bette and Gugutzer (2012) was integrated, and the motive 'enjoyment of movement' was added (following Steffgen, Fröhling, \& Schwenkmezger, 2000). 

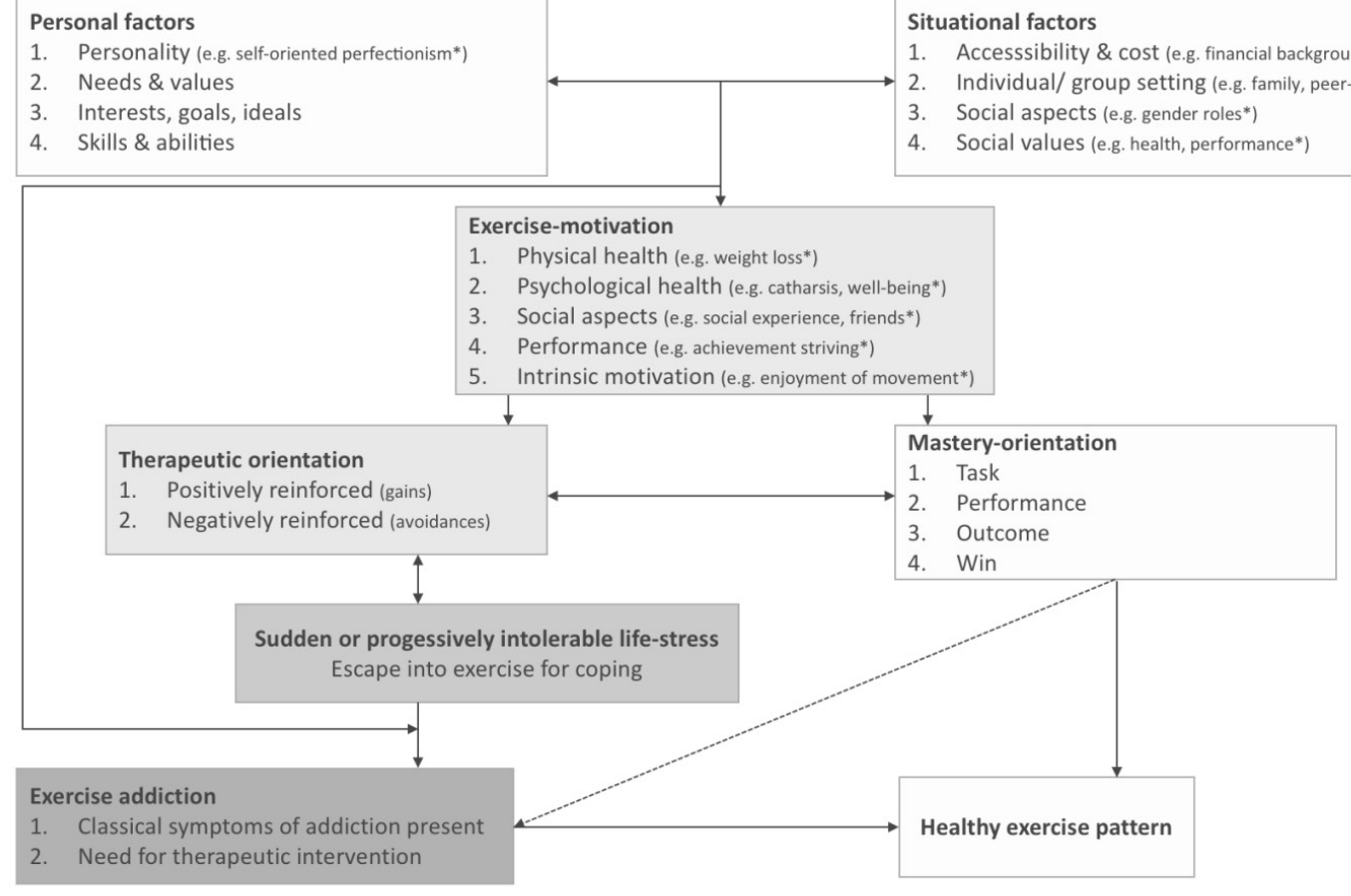

Figure 1. An interactional model to explain exercise addiction.

(modified, based on Egorov \& Szabo, 2013, p. 205, * indicates the modifications).

Based on the assumption that physiological aspects cause exercise addiction, researchers focused on endurance sports such as running (De Coverley Veale, 1987), while research in sports such as bodybuilding or fitness training focused more on psychological and socio-theoretical aspects (Hill et al., 2015; Lichtenstein, Christiansen, Elklit, Bilenberg, \& Støving, 2013; Murray, McKenzie, Newman, \& Brown, 2013). However, data for prevalence rates vary depending on factors such as measurement instruments, or sample structure (Egorov \& Szabo, 2013; Hausenblas \& Symons Downs, 2002b). Breuer and Kleinert (2009) for instance estimated the prevalence of exercise addiction as one per 1000 athletes with manifested symptoms, and one per 10000 athletes to be requiring treatment. Furthermore, the prevalence rate varies between $3 \%$ and 7 $\%$ for fitness and endurance sports, and triathlon athletes may show prevalence rates of more than 20 \% (Griffiths et al., 2015; Szabo \& Griffiths, 2007; Ziemainz, Stoll, Drescher, Erath, Schipfer, \& Zeulner, 2013).

Furthermore, it can be concluded from current research that approximately $77 \%$ of bodybuilders, powerlifters and fitness lifters and over $80 \%$ of the endurance athletes are highly committed to their sport with several symptoms of exercise addition but without necessarily exercise dependence in a strict sense (Hale et al., 2010; Ziemainz et al., 2013). Thus, exercise addiction seems to be sport independent, although endurance athletes might show higher prevalence rates. However, the risk to develop an exercise addiction in competitive sport appears to be more likely for sports where expression or weight plays an important role, such as in gymnastics, rowing, ski jumping. In these sports, rules and evaluation systems may entail a certain obsessiveness (Bette \& Gugutzer, 2012). In this context, an exercise addiction is often anorexia-associated, and the prevalence rate is usually more than $40 \%$ (Zeeck, Leonhart, Mosebach, Schlegel, Linster, \& Hartmann, 2013).

Most of the measurements that were used in current research assess psychological symptoms such as tolerance, withdrawal symptoms or lack of control (Hausenblas \& Symons Downs, 2002a). However, to record the potential of exercise addiction entirely, physical and psycho- 
OF PSYCHOLOGY

IN THE $21^{\text {st }}$ CENTURY

Vol. 13, No. 2, 2019

116

social aspects should be considered. Despite the amount, intensity and frequency of physical activity, it is also necessary to assess motivation and the potential impact of peer-groups, family or friends as well as the role of competitive sports.

Taken the aspects mentioned above together, it can be stated that the physiological and the psychological side of exercise addiction were well examined separately (Blake et al., 1984; Fraioli et al., 1980; Hill et al., 2015; Murray et al., 2013; Thompson \& Blanton, 1987). But in contrast to the affirmed relation between excessive exercise and personality traits such as perfectionism and low self-esteem, results for the affected athletes' motives are still contradictory (Hall, Kerr, Kozub, \& Finnie, 2007; Lichtenstein et al., 2013; Zeeck, Leonhart, Mosebach et al., 2013). In particular the theory of catharsis - as a part of the psychological approach - seems to be worthy for further examination. The theory is indicating excessive exercising as a way to cope with conflicts and crises, stating "that an inner (subconscious) drive to exert increased physical effort after psychological stress may exist" (Tsang \& Szabo, 2003, p. 133).

Hence, the question arises how physiological, psychological and socio-theoretical aspects are related to the presence of symptoms of exercise addiction. In detail, besides socio-demographic aspects, the role of amount, intensity and frequency of physical activity, participants motives, inspiration, and competitive activity, as well as typical symptoms of exercise addition were questioned in the context of exercise addiction using standardized instruments (Exercise Dependence Scale, EDS, Hausenblas \& Symons Downs, 2002a; Godin Leisure-Time Questionnaire, GLTQ, Godin \& Shephard, 1997; Attitude Toward Physical Activity Scales, ATPA, Kenyon, 1968; Steffgen et al., 2000).

Therefore, the primary objective of the study was to investigate the relation between motives and symptoms of exercise addiction. A second objective of the study targets the role of psycho-social aspects and their relation with symptoms of exercise addiction. Hence, the first hypothesis expected that athletes with the goals achievement striving and catharsis show higher EDS scores than athletes with the goals social experience, enjoyment of movement or health promotion (Hall et al., 2007; Lichtenstein et al., 2013; Tsang, \& Szabo, 2003; Ogles, Masters, \& Richardson, 1995). Further, the second hypothesis expected that (former) competitive athletes and athletes that have been inspired by themselves to start with their current sport show higher EDS scores (De la Vega, Parastatidou, Ruíz-Barquín, \& Szabo, 2016). No differences were expected between male and female participants (Hall et al., 2007; Müller et al., 2013). Finally, differences related to the amount and frequency of exercise and the type of sports were expected (Müller et al., 2013).

\section{Research Methodology}

\section{General Background}

The study aimed to investigate the relation between exercise addiction and physiological, psychological, and socio-theoretical aspects in the context of physical activity. A cross-section quantitative study was conducted from February to May 2018. Participants were asked for typical motives for being physically active and the sport-related inspiration.

\section{Sample}

The sample consisted of 501 participants aged 18 to 63 years $(M$ age $=26.7 \pm 8.6$ years; $56.2 \%$ male, $n=278) .348$ participants (69.4\%) were still in education and $148(29.5 \%)$ participants were employed. On average, the athletes had been active in their respective sports for 11.5 years $(S D=7.6)$ and reported three to 22 training sessions per week $(M=4.3, S D=3.2)$ with an average of 7.0 hours per week $(S D=5.4)$. At the time of the research, $n=211(42.4 \%)$ participants took part in competitions on a regular basis, $n=143(34.8 \%)$ competed on an international or national level, and $n=159$ (31.9\%) were (former) competitive athletes. Participants were contacted at university, in training groups or personally. They were asked if they would 
volunteer to participate in a study on the psychological aspect of exercise. Participants were

informed about the research objectives, and they were assured anonymity and confidentiality in the recording, analysis, and presentation of data. Including criteria for participants were the age of majority, and being regularly physically active (i.e., minimum one hour per week).

Participants furthermore reported to be engaged in 78 different sports that could be grouped into four different categories: (1) endurance sports (ES, e.g., running, cycling, swimming, triathlon, $n=166,33.5 \%$ ), (2) team sports (TS, e.g., handball, football, volleyball, hockey, basketball, water ball, canoe polo, $n=117,23.4 \%$ ), (3) individual sports (IS, e.g., track and field, gymnastics, diving, canoeing, martial arts, boxing, tennis, badminton, $n=141,28.4 \%$ ), and (4) power sports (PS, e.g., weight lifting, bodybuilding, fitness training, $n=73,14.7 \%$ ) (De la Vega et al., 2016). The category ES was further subdivided regarding their training hours: (a) less than five hours of training per week $\left(n=43, M_{E S \text { low }}=2.6, S D=1.1\right)$, (b) between five and nine hours of training per week $\left(n=67, M_{E S \text { mid }}=6.3, S D=1.4\right)$, and (c) more than ten hours of training per week $\left(n=56, M_{E S \text { high }}=15.0, S D=5.1\right)$. On average, participants' weekly exercise rate was $3271.5(S D=2481.2)$ according to participants' self-reports in the GLTEQ (see below for a description). Participants gave their written informed consent before data collection. Data collection was conducted either using an online questionnaire, or employing a pencilpaper-test. The response rate for the online questionnaire was $69.7 \%$. The response rate for the paper-pencil test was $96 \%$. Table 1 shows descriptive statistics for socio-demographic and sports-related variables.

Table 1. Descriptive statistics of the research sample.

\begin{tabular}{|c|c|c|c|}
\hline Socio-Demographic Variables & $M$ & $S D$ & Range \\
\hline Age (in years) & 26.7 & 8.6 & $18-63$ \\
\hline Years in Sport & 11.5 & 7.6 & $1-45$ \\
\hline Training Sessions per Week & 4.3 & 3.2 & $1-22$ \\
\hline Hours of Training per Week & 7.0 & 5.4 & $1-38$ \\
\hline \multicolumn{4}{|l|}{ GLTEQ* } \\
\hline Total & 3271.5 & 2481.2 & $34-20910$ \\
\hline $\mathrm{GLTEQ}_{\text {_low }}$ & 1297.9 & 544.9 & $34-2055$ \\
\hline $\mathrm{GLTEQ}_{\text {mid }}$ & 2724.6 & 425.2 & 2056-3495 \\
\hline GLTEQ $_{\text {high }}$ & 5773.6 & 2732.7 & $3496-20910$ \\
\hline Gender & $\mathrm{n}$ & $\%$ & \\
\hline Male & 278 & 56.2 & \\
\hline Female & 217 & 43.3 & \\
\hline Missing & 6 & 1.2 & \\
\hline Occupation & $\mathrm{n}$ & $\%$ & \\
\hline Pupil & 17 & 3.4 & \\
\hline Professional school & 7 & 1.4 & \\
\hline Student & 321 & 64.6 & \\
\hline Basic military service/ Alternative service & 3 & 0.6 & \\
\hline Employed & 93 & 18.7 & \\
\hline Official & 37 & 7.4 & \\
\hline Freelancer & 18 & 3.6 & \\
\hline Missing & 5 & 1.0 & \\
\hline
\end{tabular}


118

\begin{tabular}{|c|c|c|c|}
\hline Socio-Demographic Variables & $M$ & $S D$ & Range \\
\hline Type of Sport & $\mathbf{n}$ & $\%$ & \\
\hline 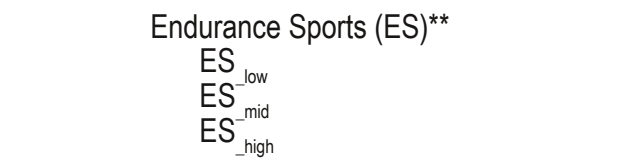 & $\begin{array}{l}166 \\
43 \\
67 \\
56\end{array}$ & $\begin{array}{c}33.5 \\
8.7 \\
13.5 \\
11.3\end{array}$ & \\
\hline Individual Sports (IS) & 141 & 28.4 & \\
\hline Team Sports (TS) & 117 & 23.4 & \\
\hline Power Sports (PS) & 73 & 14.7 & \\
\hline Missing & 4 & 0.8 & \\
\hline Competition Participation & $\mathrm{n}$ & $\%$ & \\
\hline Not at all & 142 & 28.5 & \\
\hline Seldom & 73 & 14.7 & \\
\hline Sometimes & 71 & 14.3 & \\
\hline Regularly & 211 & 42.4 & \\
\hline Missing & 4 & 0.8 & \\
\hline Competition level & $\mathrm{n}$ & $\%$ & \\
\hline Regional & 211 & 51.3 & \\
\hline National & 94 & 22.9 & \\
\hline International & 49 & 11.9 & \\
\hline Competitive sports activity & $n$ & $\%$ & \\
\hline Yes & 108 & 21.7 & \\
\hline No & 339 & 68.1 & \\
\hline No, but in the past & 51 & 10.2 & \\
\hline Missing & 3 & 0.6 & \\
\hline
\end{tabular}

Notes. ${ }^{*} G L T E Q=$ participants are divided into three groups, ${ }^{* *} E S_{\text {low }}=$ less than five hours of training per week, $E S_{\text {mid }}=b e-$ tween five and nine hours of training per week, $E S_{\text {_high }}=$ more than ten hours of training per week.

\section{Instrument and Procedures}

Exercise Dependence Scale. The Exercise Dependence Scale (EDS) is a self-report 21-item questionnaire to assess typical exercise addiction symptoms based on the clinical criteria for substance dependence (Hausenblas \& Symons Downs, 2002a). The 21 items are summarized into seven symptom scales. The symptoms are: (1) withdrawal symptoms, (2) continuance, (3) tolerance, (4) lack of control, (5) reductions in other activities. (6) intention, and (7) time (for details please see Hausenblas \& Symons Downs, 2002a). Participants respond to the items on a 6-point Likert scale ranging from 1 (never) to 6 (always).

The EDS can be examined in two different ways, either by categorizing participants into three groups ('at risk,',non-dependent, but symptomatic','non-symptomatic') or by calculating a total score. The total EDS is computed by summing up the responses to the 21 items. In this case, higher EDS scores indicate more exercise addiction symptoms. It is suggested to use the total score for the assessment of exercise dependence symptoms because there are usually quite high correlations between the seven subscales (Müller et al., 2013). The EDS is a valid instrument with good internal consistency (Cronbach's a ranging from .81 to .93) (Hausenblas \& Symons Downs, 2002b; Müller et al., 2013).

Godin Leisure Time Questionnaire. The Godin Leisure Time Questionnaire (GLTEQ) is a reliable and valid self-report instrument to assess the amount and frequency of mild, moderate and 
weekly exercise rate is calculated by weighting participants reported amount and frequency of activity at each level of intensity (mild, moderate, vigorous). A mild exercise corresponds to a metabolic equivalent (MET) between 1 and 3, whereas moderate exercise corresponds to a MET between 3 and 6, and vigorous exercise refers to a MET between 6 and 9 (Lippke \& Vögele, 2006). The calculation of weekly exercise can be accomplished by using the following formula: weekly exercise $=(2.0 \mathrm{x}$ frequency of involvement in mild exercise $\mathrm{x}$ amount of participation in mild exercise $)+(4.5 \mathrm{x}$ frequency of involvement in moderate exercise $\mathrm{x}$ amount of involvement in moderate exercise $)+(7.5 \mathrm{x}$ frequency of involvement in vigorous exercise $\mathrm{x}$ amount of involvement in vigorous exercise). For instance, a person running for 30 minutes three times a week (vigorous exercise), riding the bicycle for 60 minutes two times a week (moderate exercise), and walking for 15 minutes five times a week (mild exercise), has a weekly exercise rate of 1365 (exercise rate $=(7.5 \times 3 \times 30)+(4.5 \times 2 \times 60)+(2.0 \times 5 \times 15))$. For the statistical analysis (see below), each participant was assigned into one of three groups, depending on his/her score in the GLTEQ). A low score ranged from 34-2055, a medium score from 2056-3495 and a high score from 3496-20910.

Participants' motives for exercise and socio-demographical data. Participants' motives were assessed utilizing the Attitude Toward Physical Activity Scales (ATPA; Kenyon, 1968; Steffgen et al., 2000) with a particular emphasis on the model mentioned above (Egorov \& Szabo, 2013). The ATPA assesses different motives for being physically active such as 'health', 'performance' or 'catharsis'. Thus, with regard to the model presented in Figure 1, items were used to describe health promotion (motive: 'physiological health'), catharsis (motive: 'psychological health'), social experience (motive: 'social aspects'), achievement striving (motive:'performance') and enjoyment of movement (motive: 'intrinsic motivation'). Participants' task was first to indicate whether the different items representing the motives were relevant for being physically active (agree vs. disagree). In a second step, the participants had to rate the strength of each motive on a 3-point scale: 1 (only a positive side effect), 2 (important), 3 (very important). Every motive contained four items. Each item began with the words 'I exercise...' and ended with a motive-specific part (e.g., achievement striving: '... to compete with others'; catharsis: '... to relax physically and mentally'; social experience:'... to meet friends'; enjoyment of movement: '... to explore new things'; health promotion: '... to receive health benefits').

Finally, and in addition to common socio-demographical data (e.g., age, gender, occupation), physical and psycho-social aspects of participants' main sport (e.g., amount and frequency of training sessions, competition level, former or actual competitive state, the inspiring person to start with the current sport) were also assessed.

\section{Data Analysis}

A level of significance of $\alpha=5 \%$ was defined apriori. The independent variables were gender, type of sports (ES vs. TS vs. IS vs. PS), categorized exercise rate (GLTEQ ${ }_{- \text {low' }^{\prime}} \mathrm{GLTEQ}_{\text {-mid' }^{\prime}}$ and GLTEQ $_{\text {-high }}$ ), competitive sports activity (yes vs. no), motive estimation (achievement striving vs. catharsis vs. social experience vs. enjoyment of movement vs. health promotion), and source of inspiration to start current sport (my self vs. parents/family vs. friends vs. coach). The sum score of the EDS was used as the dependent variable. Hence, and to test the main assumptions of the current study, six separate univariate Analyses of Variance (ANOVAs) were conducted to investigate the relation of each of the six independent variables on the dependent variable. In case of an overall significant effect of one independent variable on the dependent variable, Bonferroni post-hoc tests were calculated to explore the structure of the effect. Partial eta square was calculated as effect size for all significant effects. Statistical analyses were conducted using Statistical Package for the Social Sciences (SPSS) version 24. 
OF PSYCHOLOGY

IN THE $21^{\text {st }}$ CENTURY Vol. 13, No. 2, 2019

\section{Research Results}

Results revealed an average EDS score of $56.96(S D=14.5)$ for the sample. First, no significant effect could be found between male and female athletes, $F(1,493)=0.796, p=.373, \eta_{p}^{2}=0.002$. Thus, on average, male athletes did not differ from female athletes in their EDS score.

Second, a significant effect of amount and frequency of physical activity could be found on EDS score, $F(2,498)=37.387, p<.001, \eta_{p}^{2}=0.131$. Post-hoc tests revealed differences

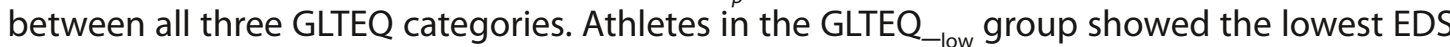
score $\left(M_{\text {EDS_SuM }}=50.68, S D=14.34\right)$ and athletes in the GLTEQ ${ }_{\text {-high }}$ exhibited the highest EDS score $\left(M_{\text {EDS SUM }}=63.49, S D=13.26\right)$. Third, a significant effect of types of sport on EDS score was found, $F(5,491)=9.354, p<.001, \eta_{p}^{2}=0.087$. In particular, athletes in the group $\mathrm{ES}_{\text {low }}$ showed the lowest EDS-score $\left(M_{E D S_{\text {_Sum }}}=47.07, S D=14.27\right)$, which was significantly different from all other type of sport categories ( $p$ ranging from $p<.001$ to $p=.034$ ). Athletes in the $\mathrm{ES}_{\text {high }}$ group showed the highest EDS score $\left(M_{\text {ED__Sum }}=66.02, S D=12.86\right)$, which was significantly different to all other type of sport categories ( $p$ ranging from $p<.001$ to $p=.02$ ). However, there were no significant differences between individual sports $\left(M_{\text {EDS _SUM }}=56.30, S D=14.59\right)$, team sports $(M=57.44, S D=12.31)$, power sports $\left(M_{\text {EDS__SUM }}=55.32, S D=15.85\right)$, and the $E_{\text {mid }}$ group $\left(M_{\text {EDS_ sum }}\right.$ $=57.84, S D=13.93$ ).

Fourth, results revealed a significant effect of competitive sports activity on EDS score, $F(2,495)=20.351, p<.001, \eta_{p}^{2}=0.076$. According to post-hoc test, competitive athletes showed significant higher EDS scores $\left(M_{\text {EDS S SUM }}=64.41, S D=12.66\right)$ compared to former competitive athletes $\left(M_{\text {EDS__SUM }}=57.25, S D=13.08, p=.008\right)$, and non-competitive athletes $\left(M_{\text {ED__sum }}=54.53\right.$, $S D=14.55, p<.001)$. However, no significant differences could be found between the athletes with no competitive background, and those who used to be competitive athletes.

Fifth, results revealed significant effects on EDS score for the motives achievement striving, $F(1,472)=22.880, p<.001, \eta_{p}^{2}=0.046$, catharsis, $F(1,425)=10.324, p=.001, \eta_{p}^{2}=0.024$, and enjoyment of movement, $F(1,430)=21.316, p<.001, \eta_{p}^{2}=0.047$. Athletes showed higher EDS-scores, when they rated these three motives as important or very important. However, no significant effects on EDS scores were found for the motives social experience and health promotion.

Finally, no significant effect emerged of inspiration on $\operatorname{EDS~score,~} F(3,467)=2.186, p=.089$, $\eta_{p}^{2}=0.014$. Thus, participants exhibited on average the same EDS score, independent of their source of inspiration to start their current sport. Table 2 presents the means and standard deviations of the EDS scores, differentiated by gender, type of sports, exercise rate, competitive sports activity, as well as motive estimation, and source of inspiration to start one's current sport.

Table 2. Descriptive statistics and results of univariate Analyses of Variance (ANOVAs) for EDS scores regarding gender, type of sports, competitive sports activity, GLTEQ, participants' motives and, inspiration.

\begin{tabular}{lcc}
\hline & \multicolumn{2}{c}{ EDS } \\
\cline { 2 - 3 } & $M_{\text {EDS_Sum }}(S D)$ & $F($ dof $) ; p ; \eta_{p}^{2}$ \\
\hline Total & $56.96(14.50)$ & $0.796(1,493) ; .373 ; 0.002$ \\
\hline Gender & & \\
$\quad$ Male, $n=278$ & $57.37(12.66)$ & \\
Female, $n=217$ & $56.20(16.57)$ & \\
\hline
\end{tabular}




\begin{tabular}{|c|c|c|}
\hline & \multicolumn{2}{|r|}{ EDS } \\
\hline & $M_{E D S \_s u m}(S D)$ & $F(d o f) ; p ; \eta_{p}^{2}$ \\
\hline Type of sports & & $9.354(5,491) ;<.001 ; 0.087$ \\
\hline $\begin{array}{l}\text { Endurance sports (ES) } \\
\begin{array}{r}\text { ES_low, } n=43 \\
\text { ES_mid, } n=67 \\
\text { ES_high, } n=56\end{array}\end{array}$ & $\begin{array}{c}\text { 47.07a,b,c,d,e (14.27) } \\
\text { 57.84a,f (13.93) } \\
\text { 66.02b,f,g,h,i (12.86) }\end{array}$ & \\
\hline Individual sports, $n=141$ & $56.30 \mathrm{c}, \mathrm{g}(14.59)$ & \\
\hline Team sports, $n=117$ & $57.44 \mathrm{~d}, \mathrm{~h}(12.31)$ & \\
\hline Power sports, $n=73$ & 55.32e,i (15.85) & \\
\hline Competitive sports activity & & $20.351(2,495) ;<.001 ; 0.076$ \\
\hline Yes, $n=108$ & $64.41 a, b(12.66)$ & \\
\hline No, $n=339$ & $54.53 a(14.55)$ & \\
\hline No, but in the past, $n=51$ & $57.25 b(13.08)$ & \\
\hline GLTEQ & & $37.387(2,498) ;<.001 ; 0.131$ \\
\hline $\begin{array}{l}\text { GLTEQ_low, } n=167 \\
\text { GLTEQ_mid, } n=166 \\
\text { GLTEQ_high, } n=167\end{array}$ & $\begin{array}{l}50.68 a, b(14.34) \\
56.68 a, c(13.05) \\
63.49 b, c(13.26)\end{array}$ & \\
\hline \multicolumn{3}{|l|}{ Motive } \\
\hline $\begin{array}{l}\text { Achievement striving } \\
\text { Important, } n=226 \\
\text { Not important, } n=248\end{array}$ & $\begin{array}{l}60.57(15.24) \\
54.46(12.52)\end{array}$ & $22.880(1,472) ;<.001 ; 0.046$ \\
\hline $\begin{array}{l}\text { Catharsis } \\
\qquad \text { Important, } n=217 \\
\text { Not important, } n=210\end{array}$ & $\begin{array}{l}60.21(14.56) \\
55.80(13.76)\end{array}$ & $10.324(1,425) ; .001 ; 0.024$ \\
\hline $\begin{array}{l}\text { Social experience } \\
\qquad \text { Important, } n=322 \\
\text { Not important, } n=157\end{array}$ & $\begin{array}{l}57.32(14.07) \\
57.71(13.93)\end{array}$ & $0.079(1,477) ; .779 ;<0.001$ \\
\hline $\begin{array}{l}\text { Enjoyment of movement } \\
\text { Important, } n=257 \\
\text { Not important, } n=175\end{array}$ & $\begin{array}{l}60.86(14.84) \\
54.54(12.55)\end{array}$ & $21.316(1,430) ;<.001 ; 0.047$ \\
\hline $\begin{array}{l}\text { Health promotion } \\
\text { Important, } n=268 \\
\text { Not important, } n=226\end{array}$ & $\begin{array}{l}57.89(13.91) \\
56.20(14.68)\end{array}$ & $1.717(1,492) ; .191 ; 0.003$ \\
\hline Inspiration & & $2.186(3,467) ; .089 ; 0.014$ \\
\hline My self, $n=269$ & $56.05(15.12)$ & \\
\hline Parents/ Family, $n=100$ & $56.49(13.22)$ & \\
\hline Friends, $n=91$ & $57.64(12.54)$ & \\
\hline Coach, $n=11$ & $66.91(17.37)$ & \\
\hline
\end{tabular}

Notes. $M_{E D S ~ s u M}=$ means of the total $E D S$ scores, $E S_{\text {low }}=$ less than five hours of training per week, $E S_{\text {mid }}=$ between five and nine hours of training per week, $E S_{\text {high }}=$ more than ten hours of training per week, GLTEQ = for statistical analysis participants are divided into three groups regarding the mean; superscript: identical letters identify the values which differed from each other based on Bonferroni post-hoc tests $(p<.05)$.

\section{Discussion}

The purpose of this research was to examine the relations between gender, type of sports, the amount and frequency of exercise (GLTEQ), competitive sports activity, motives, inspiration, and symptoms of an exercise addiction (EDS score). Therefore, 501 participants were asked either by an online-questionnaire or in person per pencil-paper-test. It was expected, 
OF PSY

that athletes with the motives achievement striving and catharsis show higher EDS scores than athletes with the motives social experience, enjoyment of movement or health promotion. The second hypothesis predicted that (former) competitive athletes and athletes that have been inspired by themselves to start with their current sports show higher EDS scores. Finally, no differences were expected between male and female participants, whereas differences related to the amount and frequency of exercise and the type of sports were expected. To investigate possible differences between the independent variables (gender, type of sports, the amount and frequency of exercise, competitive sports activity, motives, inspiration) and the dependent variable (EDS score) separate univariate Analyses of Variance (ANOVAs) were conducted. Post-hoc tests revealed no differences for gender and inspiration, but for the amount and frequency of exercise, type of sport, competitive sports activity, as well as the motives achievement striving, catharsis, and enjoyment of movement.

Although it is suggested to use the total score for the assessment of exercise dependence symptoms (Müller et al., 2013), the athletes were assigned to the three EDS categories to compare the results with previous studies. In total, $3.2 \%(n=16)$ of the participants had to be classified as 'at risk', whereas $78.2 \%(n=392)$ were categorized as 'non-dependent, but symptomatic' and $18.6 \%$ participants $(n=93)$ were classified as 'non-symptomatic'. These results are according to former studies (Hale et al., 2010; Müller et al., 2013; Zeeck et al., 2013; Ziemainz et al., 2013).

As presumed and in line with former studies no significant differences for the EDS score for male and female athletes were found (Hall et al., 2007; Müller et al., 2013). The EDS solely assesses typical symptoms of exercise addiction but does not differentiate between primary and secondary addiction. The secondary addiction is related to an eating disorder and is termed as a co-morbid disease. So, it is conceivable that differences possibly occur when the athletes record their diet (Ziemainz et al., 2013).

As expected, significant effects were found for the type of sports (De la Vega et al., 2016; Griffiths et al., 2015; Szabo \& Griffiths, 2007; Hall et al., 2007; Müller et al., 2013; Ziemainz et al., 2013). Athletes in the $\mathrm{ES}_{\text {-high }}$ group (endurance sport with more than ten hours of training per week) showed the highest EDS score and significant differences to all the other sports (e.g., individual sport, team sport, or power sports). Based on these findings this group of endurance sport has the highest potential of exercise addiction. At the same time, it must be observed that previous studies identified over $80 \%$ of endurance athletes categorized as 'non-dependent, but symptomatic' (Hale et al., 2010; Ziemainz et al., 2013). On the other hand, endurance sport requires both, regular training and a necessary commitment to exercising. So the results may be explained by considering the dedication and the engagement in the activity of endurance athletes (De la Vega et al., 2016; Müller et al., 2013).

Significant effects were also found for competitive sports activity. Competitive athletes showed the highest EDS scores while former competitive athletes did not show higher EDS scores compared to non-competitive athletes. A possible explanation for both might be the high commitment of competitive athletes to their sport during their career. This commitment may end when the career has ended. So, potential symptoms of an exercise addiction could decline (Bette \& Gugutzer, 2012).

As expected, the motive achievement striving seems to be related to exercise addiction (Hall et al., 2007; Lichtenstein et al., 2013; Ogles et al., 1995). In this study, those athletes who rated the motive as important or very important showed higher EDS scores. In this context, the motive achievement striving may explain the higher scores of competitive atheletes (De la Vega et al., 2016). On the other hand, achievement striving can be seen as a part of the personality assigned to the trait conscientiousness, resulting in high perfectionism or the Mastery-orientation path (Figure 1) and the potential to become addicted (Egorov \& Szabo, 2013; Hausenblas, \& Giacobbi, 2004; Lichtenstein et al., 2013).

A novel finding refers to the motive catharsis. As expected, athletes with this motive showed higher EDS scores. Excessive exercise can be seen as a way to cope with conflicts or crises (Tsang \& Szabo, 2003). Another novel finding refers to the motive enjoyment of move- 
ment. This motive seems to influence the EDS score as athletes who rated this motive as important or very important, showed higher EDS scores. The underlying intrinsic motivation

Based on the results, inspiration did not affect the EDS score. It was expected, that athletes that have been inspired by themselves to start with their current sport show higher EDS scores, than athletes that were inspired by other persons (i.e., parents, friends, coach). Potentially, the socialization process during the practice and the combination with other situational and personal factors such as gender roles or personal values may produce different results. The interaction between personal and situational factors is still described as 'black-box' (Egorov \& Szabo, 2013). Future research could focus more on the combined assessment of personal and situational factors.

Finally as expected, but contrary to former studies, the results showed no relation of the motives of social experience and health promotion and the EDS score (Hausenblas \& Symons Downs, 2002b; Ogles et al., 1995). A possible explanation might be, that athletes with these motives exercise less intensive and extensive or they take part in team sports more frequently. In sports, such as volleyball, handball or basketball social interactions are more pronounced.

The assessment of different motives gives a deeper insight into the goals of possible addicted athletes. Nevertheless, the various motives could be assessed in more detail as in this research the motive achievement striving also comprised one item that could also stand for physical health ('I exercise to lose respectively maintain weight'). However, the findings underline and even expand the presented interactional model to explain exercise addiction as intrinsic motivation may play a role in the developmental process (Egorov \& Szabo, 2013). In these particular cases athletes with the stronger motive enjoyment of movement showed higher EDS scores.

Quantitative research as used in the present study is always limited due to the data assessment itself. Although the questionnaire assessed further data regarding the type of sports, motives, and the amount, intensity and frequency of physical activity, any information about the participants' personality that might give a further explanation of the results was not assessed. On the other hand, EDS is solely a screening instrument, identifying athletes' difficulties regarding their affective reaction, respectively regulation to typically addictive symptoms, such as tolerance, withdrawal symptoms, continuance, and lack of control. High EDS scores indicate more exercise addiction symptoms (Hausenblas \& Symons Downs, 2002a). To distinguish between addicted and highly committed athletes, a closer look at the separate subscales is necessary. Because for committed athletes the obsessiveness and the related lack of control are missing. Otherwise, qualitative interviews can prevent a false positive result (Müller et al., 2014).

\section{Conclusions}

Just like regular physical activity results in many different physiological and psychological benefits, peoples' motives to exercise are different. But despite the numerous positive benefits regular exercise can be harmful and become obsessive under some circumstances. Associated to this are typical symptoms such as the reduction of other activities, lack of control or even withdrawal symptoms. Referring to peoples' motives to exercise, the present research could show that athletes with the motives of social experience and health promotion do not show any symptoms of exercise addiction. In contrast, the motives of achievement striving, catharsis and enjoyment of movement supposed to play a role in the process of exercise addiction, thereby having implications for competitive athletes, because this sample group showed higher EDS scores than non-competitive athletes. A closer look regarding the subscales may help coaches to distinguish between highly committed athletes with normal scores and affected athletes with higher scores on the subscales withdrawal symptoms, lack of control and reduction of occupational, social and recreational activities.

Also, a novel finding refers to the motives of catharsis and enjoyment of movement. 
Athletes with these motives showed higher EDS scores. It is conceivable that the two motives are related. Excessive exercising as a way to cope with conflicts and crises (motive: catharsis) may cause enjoyment at the same time. To achieve the same effect, athletes invest more time and do not become aware of the increasing lack of control. To find other satisfying activities or ways to solve occupational or personal problems could be a chance to regain control.

Finally, although the psycho-social aspect inspiration had no effect in the present research, the combination of situational and personal factors needs to be investigated in future research. Furthermore, the change of motives during the practice, such as from health promotion to achievement striving or increased importance of values could also explain the process of exercise addiction. In this line, the social impact of peers, friends, or family is still unclear. Particularly the exercise addiction-related encompassing fixation and its associated development of an ingroup-identity - where affected athletes predominantly surround themselves with persons with the same interest - is worthy of being investigated further.

To escape a substance-related addiction, complete abstinence is recommended. To escape an exercise addiction, the recommendation could be to find other activities, that entail enjoyment and well-being.

\section{Acknowledgements}

The authors want to thank Christoph Paul Clauß for his support.

\section{References}

Allegre, B., Souville, M., Therme, P., \& Griffiths, M. (2006). Definitions and measures of exercise dependence. Addiction Research and Theory, 14, 631-646.

Berczik, K., Szabó, A., Griffiths, M. D., Kurimay, T., Kun, B. Urbán, R., \& Demetrovics, Z. (2011). Exercise addiction: Symptoms, diagnosis, epidemiology, and etiology. Substance Use \& Misuse, 47(4), 403-417. doi: 10.3109/10826084.2011.639120.

Bette, K.-H., \& Gugutzer, R. (2012). Sport als Sucht - Zur Soziologie einer stoffungebundenen Abhängigkeit [Sports as addiction: On the sociology of a non-substance dependence]. Sport und Gesellschaft-Sport and Society, 9(2), 107-130.

Blake, M. J., Stein, E. A., \& Vomachka, A. J. (1984). Effects of exercise training on brain opioid peptides and serum LH in female rats. Peptides, 5, 953-958.

Breuer, S., \& Kleinert, J. (2009). Primäre Sportsucht und bewegungsbezogene Abhängigkeit Beschreibung, Erklärung, Diagnostik [Primary exercise addiction and sports-related dependence. Description, explanation, diagnostics]. In D. Batthyàny \& A. Pritz (Hrsg.), Rausch ohne Drogen: Substanzungebundene Süchte [High without drugs: non-substance addiction] (pp. 191-218). Wien: Springer Vienna.

Clow, A., \& Edmunds, S. (2014). Physical activity and mental health. Champaign, IL: Human Kinetics.

De Coverley Veale, D. M. W. (1987). Exercise dependence. British Journal of Addiction to Alcohol \& Other Drugs, 82, 735-740.

De la Vega, R., Parastatidou, I. S., Ruíz-Barquín, R., \& Szabo, A. (2016). Exercise addiction in athletes and leisure exercisers: The moderating role of passion. Journal of Behavioral Addictions, 5(2), 325-331. doi:10.1556/2006.5.2016.043.

Dishman, R. K. (1985). Medical psychology in exercise and sport. Medical Clinics of North America, 69(1), 123-143. doi:10.1016/S0025-7125(16)31061-6.

Egorov, A. Y., \& Szabo, A. (2013). The exercise paradox: An interactional model for a clearer conceptualization of exercise addiction. Journal of Behavioral Addictions, 2(4), 199-208. doi: 10.1556/JBA.2.2013.4.2.

Fraioli, R., Moretti, C., Paolucci, D., Alicoccio, E., \& Crescenzi, F. (1980). Physical exercise stimulates marked concomitant release of beta-endorphin and ACTH in man. Experientia, 36, 987-989. 
Griffiths, M. D., Urbán, R., Demetrovics, Z., Lichtenstein, M. B., de la Vega, R., Kun, B., Ruiz-Barquín, R., Youngman, J., \& Szabo, A. (2015). A cross-cultural re-evaluation of the Exercise Addiction Inventory (EAI) in five countries. Sports Medicine, 1, 5-12. doi: 10.1186/s40798-014-0005-5.

Godin, G., \& Shephard, R. J. (1997). Godin Leisure-Time Exercise Questionnaire. Medicine and Science in Sports and Exercise. Supplement, S36-S38.

Hale, B. D., Roth, A. D., DeLong, R. E., \& Briggs, M. S. (2010). Exercise dependence and the drive for muscularity in male bodybuilders, power lifters, and fitness lifters. Body Image, 7, 234-239. doi:10.1016/j.bodyim.2010.02.001.

Hall, H. K., Kerr, A. W., Kozub, S. A., \& Finnie, S. B. (2007). Motivational antecedents of obligatory exercise: the influence of achievement goals and multidimensional perfectionism. Psychology of Sport and Exercise, 8, 297-316.

Hausenblas, H. A., \& Giacobbi, P. R. (2004). Relationship between exercise dependence symptoms and personality. Personality and Individual Differences, 36, 1265-1273. doi:10.1016/S0191-8869(03)00214-9.

Hausenblas, H. A., \& Symons Downs, D. (2002a). How much is too much? The development and validation of the exercise dependence scale. Psychological Health, 17, 387-404. doi:10.1080/0887044022000004894.

Hausenblas, H. A., \& Symons Downs, D. (2002b). Exercise dependence: A systematic review. Psychology of Sport and Exercise, 3, 89-123. doi: 10.1016/S1469-0292(00)00015-7.

Hill, A. P., Robson, S. J., \& Stamp, G. M. (2015). The predictive ability of perfectionistic traits and selfpresentational styles in relation to exercise dependence. Personality and Individual Differences, 86, 176-183.

Kenyon, G. S. (1968). Six scales for assessing attitude toward physical activity. Research Quarterly, 39, 566-574.

Lichtenstein, M. B., Christiansen, E., Elklit, A., Bilenberg, N., \& Støving, R. K. (2013). Exercise addiction: A study of eating disorder symptoms, quality of life, personality traits and attachment styles. Psychiatry Research, 215(2), 410-416. doi: 10.1016/j.psychres.2013.11.010.

Lippke, S., \& Vögele, C. (2006). Sport und körperliche Aktivität [Exercise and physical activity]. In B. Renneberg \& P. Hammelstein (Hrsg.), Gesundheitspsychologie [Health psychology] (pp. 195-2016), Heidelberg: Springer Medizin Verlag. doi: 10.1007/978-3-540-47632-0_12.

Müller, A., Claes, L., Smits, D., Gefeller, O., Hilbert, A., Herberg, A., Müller, M., Hofmeister, D., \& de Zwaan. M. (2013). Validation of the German Version of the Exercise Dependence Scale. European Journal of Psychological Assessment, 29(3), 213-219. doi: 10.1027/1015-5759/a000144.

Müller, A., Cook, B., Zander, H., Herberg, A., Müller, V., \& de Zwaan, M. (2014). Does the German version of the Exercise Dependence Scale measure exercise dependence? Psychology of Sport and Exercise, 15(3), 288-292. doi:10.1016/j.psychsport.2013.12.003.

Murray, A. L., McKenzie, K., Newman, E., \& Brown, E. (2013). Exercise identity as a risk factor for exercise dependence. British Journal of Health Psychology, 18(2), 369-382.

National Center for Health Statistics (2012). Healthy People 2010 Final Review. Hyattsville, MD.

Ogles, B. M., Masters, K. S., \& Richardson, S. A. (1995). Obligatory running and gender: An analysis of participative motives and training habits. International Journal of Sport Psychology, 26, 233-248.

Szabo, A. (1995). The impact of exercise deprivation on well-being of habitual exercisers. The Australian Journal of Science and Medicine in Sport, 27, 68-75.

Szabo, A. (2010). Exercise addiction: A symptom or a disorder? New York, NY: Nova Science.

Steffgen, G., Fröhling, R., \& Schwenkmezger, P. (2000). Motive sportlicher Aktivität. Psychometrische Untersuchungen einer Kurzform der ATPA-D-Skalen [Motives in physical activity. Psychometrics of the short version of the ATPA-D-scales]. Sportwissenschaft, 30, 408-421.

Szabo, A., \& Griffiths, M. (2007). Exercise addiction in British sport science students. International Journal of Mental Health and Addiction, 5, 25-28. doi: 10.1007/s11469-006-9050-8. 
OF PSYCHOLOGY

IN THE $21^{\text {st }}$ CENTURY

Vol. 13, No. 2, 2019

126

Thompson, J. K., \& Blanton, P. (1987). Energy conservation and exercise dependence: A sympathetic arousal hypothesis. Medicine and Science in Sports and Exercise, 19, 91-97.

Tsang, T. C. E., \& Szabo, A. (2003). Motivation for increased self-selected exercise intensity following psychological distress: Laboratory based evidence for catharsis. Journal of Psychosomatic Research, $55(2), 133$

World Health Organization (WHO). (2010). Global recommendations on physical activity for health. Geneva, Switzerland.

Zeeck, A., Leonhart, R. Mosebach, N., Schlegel, S., Linster, H. W., \& Hartmann, A. (2013). Psychopathologische Aspekte von Sport - Eine deutsche Adaptation der „Exercise Dependence Scale“(EDS-R) [Psychpathological aspects in physical activity - the german adaptation of the „Exercise Dependence Scale"(EDS-R)]. Zeitschrift für Sportpsychologie, 20(3), 94-106.

Ziemainz, H., Stoll, O., Drescher, A., Erath, R., Schipfer, M., \& Zeulner, B. (2013). Die Gefährdung zur Sportsucht in Ausdauersportarten [The potential of exercise addiction in endurance sports]. Deutsche Zeitschrift für Sportmedizin, 64(2), 57-64. doi: 10.5960/dzsm.2012.057.

Received: April 11, 2019

Accepted: November 10, 2019

Nadja Walter Dr., Post-Doc, Leipzig University, Faculty of Sport Science, Institute of Sport Psychology and Sport Pedagogy, Jahnallee 59, 04109 Leipzig, Germany.

E-mail: nadja.walter@uni-leipzig.de

Website: http://www.spowi.uni-leipzig.de/fakultaet/institute-fachgebiete/

psychpaed/personal/dr-nadja-walter/dr-nadja-walter/

Thomas Heinen Dr. habil., Professor, Leipzig University, Faculty of Sport Science, Institute of Movement and Training Science in Sport I, Jahnallee 59, 04109 Leipzig, Germany.

E-mail: thomas.heinen@uni-leipzig.de 